\title{
NARRATIVA(S) SOBRE EL SINDICALISMO EN CHILE. NOTAS A PARTIR DEL PENSAMIENTO DE WALTER BENJAMIN
}

\author{
Narrative(s) about trade unionism in Chile. \\ Notes from the thought of Walter Benjamin \\ Dasten Julián Vejar*
}

"El don de encender en lo pasado la chispa de la esperanza sólo es inherente al historiador que esté convencido de que ni los muertos estarán seguros ante el enemigo si es que éste vence. $\mathrm{Y}$ ese enemigo no ha cesado de vencer". Walter Benjamin.

\section{RESUMEN}

El sindicalismo ha sido sujeto y objeto de serios debates en el Chile contemporáneo. Su innegable determinación estructural en la dictadura militar de (1973-1989) ha generado una serie de discursos que asimilan la llamada crisis sindical con éste período en particular. En éste texto revisamos las relaciones en cuanto a la permanente remembranza justificatoria de cierta inactividad en el sindicalismo, a partir de reconocer el rol del sindicalismo y el movimiento de trabajadores en el proceso de transición democrática.

Palabras clave: Sindicatos, Dictadura, Memoria, Remembrar.

\begin{abstract}
Unionism has been subject and object of serious debate in contemporary Chile. His undeniable structural determination by the military dictatorship (1973-1989) has generated a series of speeches that called about a "union crisis" assimilate with this period in particular. In this article we review the relationship in terms of this permanent justifying remembrance of some inactivity in trade unionism, beginning to recognize the role of unions and the labor movement in the process of democratic transition.

Keywords: Unions, Dictatorship, Memory, Remembrance.

\footnotetext{
*Departamento de Sociología y Ciencias Políticas, Facultad de Ciencias Sociales, Universidad Católica de Temuco. Temuco, Chile. Correo electrónico: dasten@gmail.com

Artículo recibido el 9 de julio de 2013. Aceptado el 4 de noviembre de 2013.
} 


\section{INTRODUCCIÓN}

En la actualidad, pareciese ser posible distinguir un consenso generalizado en la producción de las ciencias sociales en Chile con respecto al movimiento sindical chileno, el cual consiste en reconocer en la dictadura militar de Pinochet un episodio traumático para su constitución y desarrollo. Este "consenso del debilitamiento" se basa, principalmente, en el reconocimiento de la des-configuración del anterior rol protagónico del sindicalismo en el campo político, y de su desfiguración en su posición en las relaciones laborales, lo cual lo habría sumergido en un espacio de resistencia aletargada y de socavamiento de sus principales pilares históricos.

También se hace posible identificar, como parte de este consenso, los efectos estructurales de una cruda restructuración productiva, guiada por políticas neoliberales de des-industrialización, (re)privatización y transnacionalización, la cual sentó una transformación sistémica de las condiciones y formas de trabajo -fenómenos de precarización y flexibilización laboral-, y con ello, la erosión del trabajo como mecanismo de integración social.

La construcción de este consenso se encuentra solventada en la interacción de diversos análisis y propuestas teórico-políticas las cuales han generado una historia coherente-lineal del "sindicalismo en dictadura", hasta pasar, en la actualidad, ha constituir una narrativa hegemónica en el tratamiento del "sindicalismo en democracia". A la vez, es posible constatar, como ciertas concepciones con respecto al sindicalismo, en tanto perspectivas historiográficas - las cuales documentan el pasado desde una construcción del presente- se encuentran enlazadas en una recursividad ideológica que acomoda el tratamiento de esta realidad ("pasada") como apéndice de su narrativa ("presente").

Así es como la matriz de este consenso, en la interrelación entre "la historia" y su narración hegemónica, permite identificar vertientes de análisis del "pasado" -como "objeto de estudio"-, que movilizan diversas justificaciones, explicaciones y racionalizaciones de la realidad del sindicalismo en su "presente" (Campero, 2000; Salinero, 2004; 2006; Frías, 2008; López, 2009), lo cual ha hecho y hace que el sindicalismo se encuentre atrapado en un torrente discursivo-narrativo que reúne los diversos intentos de apropiarse de su condición de (no) actor, y de situarlo en un contexto profundamente contradictorio y complejo.

Es de acuerdo con este escenario que en el presente texto nos interrogamos, desde una perspectiva crítica, sobre de la producción de narrativas de segundo orden acerca del sindicalismo, como producción multidimensional y de remembranza del legado dictatorial. Nuestro objetivo es dar cuenta del proceso de modelación y de reafirmación de las lógicas dictatoriales en el campo laboral, entre "la tradición" y "la historia" (Benjamin, 2007), en su rescate, mitos, tabúes y olvido histórico.

Realizamos éste análisis desde de la teoría crítica, respecto a las tesis de la historia de Walter Benjamin, y de su relectura por parte de Frederic Jameson (1969; 1972; 2006) y Terry Eagleton (1998), con la idea de generar un acercamiento, desde la nostalgia y la memoria, al campo y lugar simbólico en disputa en las construcción de las relaciones laborales y el sindicalismo. 


\section{SOBREVIVIENDO A UNA DICTADURA MILITAR Y AL NEOLIBERALISMO}

La reestructuración social de la dictadura militar en Chile y la imposición del modelo neoliberal se plasmó en el cambio en las políticas sociales, laborales y de protección social, y en la política económica de reestructuración productiva, privatizaciones, el "tratamiento de shock monetario", liberalización financiera, del capital y comercial, teniendo como objetivo estratégico lograr una transformación profunda de la sociedad chilena y el establecimiento de una matriz de control que garantizara condiciones óptimas a la restitución y ejercicio del poder de la clase empresarial nacional y transnacional.

Esto significó el fortalecimiento de una economía primario exportadora, la influencia del capital transnacional, una sociedad altamente polarizada y con profundas desigualdades sociales, con nuevas variantes y mecanismos de disciplinamiento (normatividad/represión), con una negación efectiva en las prácticas y el pensamiento político opositor al régimen (Garretón, 2007). Conjunto a ello se extendía una sofistica red de represión de los movimientos sociales y populares, con un ejercicio monopólico descarnado de la violencia política por parte del Estado (Salazar y Pinto, 1999).

Para el sindicalismo, las consecuencias fueron nefastas. La tradición político militante que acompañaba las formas de identificación y de transmisión de una "cultura obrera” en relación al gobierno y sus partidos políticos, fue borrado por medio de la persecución, la violencia política y física, etc., desarticulando la estrategia del sindicalismo y todo el poder organizacional que había movilizado en las décadas anteriores, desde su participación orgánica subordinada en el gobierno de Salvador Allende, hasta el foco de radicalización clasista que promovió formas de control obrero de la producción en el gobierno de la Unidad Popular (Gaudichaud, 2003: 6). Por otra parte se sumaba la institucionalización de una estrategia disciplinar en el trabajo (Julián, 2012b), desmontando los imaginarios de reconocimiento de la clase trabajadora, sumado al prohibicionismo y el intervencionismo de la dictadura en materia organizacional (Julián, 2012a).

En esta misma dirección apuntaron las reformas en el plano de las relaciones laborales, que se sintetizaron en el Plan Laboral del año 1979. Éste involucraba una política asociada al irrespeto de las libertades sindicales y a la protección de los derechos de los trabajadores (Rojas, 2009), con un abierto tenor pro-empresarial (Zapata, 2004: 5), identificándose con la denominada "flexibilización laboral", la matriz y modelo de cambio que permitiría moldear y facilitar la emergencia de procesos de localización productiva y de inversión. Si bien se reconoció la legalidad de sindicalismo ${ }^{1}$, tan solo permitió actividades restringidas en la empresa local y limitando el poder y el control de los sindicatos sobre sus líderes, miembros y puestos, incluyendo de forma restrictiva el derecho a negociación colectiva y a huelga (Zapata, 2004: 141-142).

Pese a que no podemos aquí hacer una historia del sindicalismo en dictadura, pero recogiendo distintos autores sobre el sindicalismo en Chile (Aguiar, 2008; Campero y Valenzuela; 1981; Valenzuela, 1986; Touraine, 1989; Zapata; 1992; 2004; Drake; 1996;

\footnotetext{
${ }^{1}$ Esto en medio de un contexto de presiones populistas al interior de la Junta Militar, y internacionales como las amenazas de boicot a los productos chilenos por parte de la AFL-CIO norteamericana (Valenzuela, 1986) que hacían insoportable la represión al sindicalismo en la forma en que se desarrollaba, hasta ese momento.
} 
2003; Salazar y Pinto, 1999; Campero, 2000; Salinero, 2004; 2006; Frías, 2008; Rojas, 2009; Ulloa, 2003), podemos resumir su trayectoria en cuatro etapas importantes:

Prohibicionismo y persecución (1973-1978): es una etapa marcada por el ejercicio de la persecución, tortura, exilio, desaparición, etc., de los cuadros y dirigentes del movimiento sindical. El prohibicionismo y la ilegalidad de las organizaciones sindicales formales, pero con el funcionamiento de organizaciones informales y nucleares de trabajadores. En el primer período (1973-1978) vemos algunos fenómenos de la reconstitución en la ilegalidad del movimiento sindical (Aguiar, 2008: 24-27), tales como la formación en 1975 de la Coordinadora Nacional Sindical (CNS), la cual agrupó a la izquierda y sectores del partido Demócrata Cristiano ${ }^{2}$ (DC), como "un núcleo de convergencia alrededor del Centro de Estudios Laborales (CEL)", a partir de la reorganización de la antigua Confederación de empleados Particulares $(\mathrm{CEPCH})$, la cual era de carácter independiente. Se gestó igualmente como grupo el Frente unitario de Trabajadores, (FUT), de orientación católica, ligado a la Central mundial de Trabajadores (CMT) y a su rama regional, la Central Latinoamericana de Trabajadores (CLAT) (Frías, 2008); en 1975 se celebra el primero de Mayo, lo que muestra "que, a menos de dos ańos del pronunciamiento militar, estas fuerzas sindicales lograban re-articularse en cierta medida y que eran capaces de promover la movilización de bases" (Campero y Valenzuela, 1981); a ello se suma la primera confluencia de dirigentes sindicales de oposición (1976), con el objetivo de exigir al gobierno militar la restitución de la democracia, el desarrollo de huelgas de "trabajo lento" y los "viandazos"; la protesta pública y el rol de la Iglesia, sumado a diversos conflictos y huelgas en diversos sectores de la producción (Aguiar, 2008).

Nueva institucionalización (1979-1981): la aplicación de la reforma laboral, y el reconocimiento de las organizaciones sindicales, con la institucionalización de un sistema de relaciones profundamente asimétrico y que debilitaba el poder organizacional e institucional de los trabajadores (2003: 14). Si bien reconoció la legalidad del sindicalismo, tan solo permitió actividades restringidas en la empresa local, limitando el poder y el control de los sindicatos sobre sus líderes, miembros y puestos, restringiendo sus negociaciones colectivas y sus huelgas (Zapata, 2003; Julián, 2012b).

Crisis económicas (1981-1983): un proceso de tensión estructural, donde se revitalizó el sindicalismo que había sido aislado y reducido al espacio empresarial, para comenzar un proceso de recomposición gradual y de asociación orgánica con otros actores sociales. La crisis de la deuda que azotó al conjunto de América Latina el año 1982, y que si bien socavó la base del sustento del Régimen militar y de su ideología neoliberal, produce fenómenos contradictorios en cuanto al accionar y (des)composición del movimiento sindical chileno. La crisis, de forma diversa, "incidió en desafiliaciones en el bloque en el poder o conjunto de sectores dominantes y en un impulso para la acción movilizadora y contestataria del Sindicalismo, que dinamizará la acción de los Partidos, pese a la represión reinante y que concitará la declaración de estados de Sitio, etc.” (Frías, 2008: 99).

\footnotetext{
${ }^{2}$ La Democracia Cristiana además tenía un grupo que era conocido como "el Grupo de los Diez", los que recién en 1975 sufrieron un progresivo agrietamiento al interior de su dirigencia sindical, que apostaba a la colaboración con el gobierno en la perspectiva de una rápida vuelta a la democracia con su protagonismo; y en segundo lugar en un mayor distanciamiento con el gobierno, que irá conduciendo a una convergencia sindical más activa de oposición a la dictadura. (Aguiar, 2008: 2830). Tan solo en mayo de 1976 el "grupo de los Diez", genera un documento público, en que manifiesta el fin de su "apoyo condicionado" al gobierno. "la significación de este hecho estuvo en que constituyó el primer paso de ruptura efectiva entre la dirigencia sindical de esta corriente política y el régimen militar".
} 
Movilización por la democracia (1983-1989): en el medio del anterior proceso de recomposición, la relación entre sindicalismo, partidos políticos y actores sociales se dinamiza, y constituye al sindicalismo en uno de los actores de movilización y ataque a la dictadura militar, en búsqueda de la transición democrática. Desde la centralidad de la convocatoria del año 1983-1989 podríamos decir que el movimiento sindical y la clase obrera jugaron un rol importante en debilitar las bases del régimen militar. Desde su centralidad en la convocatoria de otros sectores populares en las primeras Jornadas de Protesta (1983-1985), hasta su directa subordinación a los partidos políticos (19851989), mostró un interesante proceso de alianza y colaboración con los sectores populares (Zapata, 1992; 2004), lo cual dejó una interesante experiencia de extensión del núcleo laboral de la convocatoria en la lucha por la democracia (Zapata, 1992; Drake, 1996), y de alimentación del progreso de reunificación en la Central Unitaria de Trabajadores (1988).

Desde la "narración" que hemos presentado a modo introductorio, podríamos decir que se incorporan una serie de problemáticas y núcleos que nos harían hablar de UN sindicalismo, homogéneo, en su constitución y su movilización, con una cierta continuidad y linealidad para domesticar su pasado y narrarlo, ya que lo que he expuesto hasta ahora es más bien un marco muy general que integra diversas vertientes de la historiografía sindical chilena $^{3}$, las cuales comparten, por ejemplo, la linealidad que "cuenta" al sindicalismo pasando por fases: prohibicionismo y violencia(s); adaptación y recomposición; trauma y nueva institucionalidad; shock económico y crisis; movilización sindical-popular y subordinación política, de forma de hacerlo inteligible a un periodo transicional que destaca por el desarrollo de una estrategia neo-corporativa de acuerdos con el bloque de gobierno ${ }^{4}$.

Pese a lo interesante del anterior proceso, en Chile se ha desarrollado una argumentación sociológica y una narrativa historiográfica, las cuales se han encargado de justificar y de prefigurar, a partir de las transformaciones estructurales del modelo de producción y del mercado de trabajo, una reconversión de las prácticas del movimiento sindical que la someterían a un proceso de crisis y de extinción. Ésta realiza un juego de "doble filo", al basar su fundamentación (de la pérdida de centralidad del trabajo, fin del trabajo, descomposición de colectividades, individualización, etc.) en: a) la restructuración económica (De la Garza, 2001), con una profunda concepción "fatalista” de sus impactos y b) la dictadura militar, como una sombra sobre-explicativa, (estilo mónada leibniziana) de la multi-dimensional "crisis del sindicalismo" en la actualidad. Muchas preguntas parecen entrecruzarse y sobreponerse a esta "narración": ¿Por qué será que los estudios referidos al sindicalismo retornan permanente e insistentemente a la dictadura? ¿Por qué

\footnotetext{
${ }^{3}$ Con respecto a esta historiografía, vemos uno de los males del historicismo, el cual "se contenta a sí mismo con establecer una conexión causal de varios momentos en la historia". Según Benjamin (2007: 263) "ningún hecho es ya histórico por ser causa. Llegará a serlo póstumamente a través de datos que muy bien pueden estar separados de él por milenios. El historiador que parta de ello, dejará de desgranar la sucesión de datos como un rosario entre sus dedos. Captará la constelación en la que con otra anterior muy determinada ha entrado en su propia época”.

${ }^{4}$ Destacamos que la bibliografía usada anteriormente hace referencia hasta el año 2009, por lo que no integra directamente el periodo de "un presente" gobernado por una coalición de partidos de derecha (2010-2013), donde esta estrategia se encuentra en crisis.

${ }^{5}$ El impacto de este proceso también lo hemos constatado reproducido en las entrevistas realizadas a dirigentes sindicales, en el marco de nuestra investigación de Doctorado, las cuales muestran ampliamente una "narrativa" atravesada por el fatalismo, la inactividad y la precariedad desde la "voz" de los/as mismos/as trabajadores/as.
} 
en Chile, el mercado de trabajo sigue explicándose a partir de las reformas laborales de 1979 y las transformaciones estructurales neoliberales? ¿Remembrar se vuelve un ejercicio obsesivo o es una explicación socio-histórica necesaria? (Ricoeur, 2002).

Con respecto a este tipo de remembranza, queremos abrir el debate acerca del rescate de la historia y la tradición, de acuerdo a los aciertos teóricos de Walter Benjamin, y el complemento analítico de Fredric Jameson y Terry Eagleton, los cuales creemos pueden ofrecernos un profundo respaldo teórico a la hora de sistematizar este proceso y de contestar algunas interrogantes del presente.

\section{NARRATIVAS DESDE “EL PRESENTE”}

Partamos de la noción que nos entrega Benjamin de la historia (2007: 261), como "el sujeto de una estructura cuyo sitio no es homogéneo, un tiempo vacío, pero un tiempo llenado por la presencia del ahora (Jetztzeit)". En esta "presencia del ahora", es que "el materialista histórico sólo se acerca a un tema histórico, solo cuando lo encuentra como mónada. En su estructura encuentra la señal de un cese mesiánico del acontecer o, dicho de otra forma, una oportunidad revolucionaria en la lucha por el pasado oprimido" (Benjamin, 2007: 263).

Podríamos decir, que nuestro "tema histórico" se desprende a partir de lo que llamamos la mónada dictatorial ${ }^{6}$, como un espacio lineal narrativo, producto de una configuración cristalizada (Benjamin, 2007; 262) en la construcción de la historiografía sindical en Chile. La fuerza reificadora de la dictadura, como objeto de rememoración y de producción de sujetos (obstinados) rememorantes, los cuales se destacan por subjetividades organizadas en función del olvido, el perdón y el consenso, como formas de redención (Benjamin, 2007: 254), hacen que creamos necesario sentar la "oportunidad revolucionaria" por restituir la lucha por "el pasado oprimido" abriendo un campo de perturbación y explosión de la monada, desde la complejidad y heterogeneidad del sindicalismo, y de las fuentes de esta subjetivación del pasado.

Nuestra estrategia para dar cuenta de este "pasado oprimido", está marcada por la violencia epistémica de desarticular estas prácticas en el presente. Como señala Terry Eagleton (1998: 77) "cualquier intento de recuperar directamente el pasado de forma noviolenta solo resultará en una paralizante complicidad con él”, lo cual convierte la lucha por el pasado en una temática dinámica del presente, mediada por la configuración en la que excavamos este pasado, la crisis del consenso pasivo (Julián, 2013a) como fuente de rememoración.

Desde este contexto, el "pasado oprimido" aparece como una interrogante e interpelación, desde el presente, referente a su identificación (como propia), o como residuo que vuelve en el marco del conflicto social, y de las redefiniciones internas de las relaciones de poder y de perspectivas estratégicas del sindicalismo (Julián, 2012a). En éste proceso el pasado se constituye como un espacio discursivo y material de disputas, ya que "para nosotros el destino del pasado debe ser incluido en la imagen que tenemos de él, como

\footnotetext{
${ }^{6}$ Aquí se puede hacer un paralelo con la idea de Theodor Adorno y su teoría de la estética (2004), o lo que Jameson (2010:
} 279-288) llamará, desde la superación de la dialéctica sujeto/objeto adorniana, "la mónada como lo cerrado abierto". 
tristeza o como derrota, o como masacre, o por el contrario, como una sensación apenas perceptible del aire de la aurora. Pero resulta difícil cuadrar esto con el tabú consistente en marginar las concepciones del pasado como decadencia o regresión y voltea la polémica en otra, e una espiral ascendente" (Jameson, 2011: 44).

El tabú, "de aquello de lo que no hablamos", como práctica de las "formas de no hablarlo", expulsando, marginando, y colocando en la cornisa de la memoración, entre el olvido y la liquidación del pasado, involucran negativamente, en resumidas cuentas, una estrategia de dominio de "lo hablado" y "las formas de hablarlo". Por ejemplo, la negación de la derrota del sindicalismo en el período "transicional" democrático, y el reconocimiento de su derrota ante la dictadura, hablan de dos formulaciones del pasado, y de dos imágenes que se transponen y yuxtaponen para dar cuenta de un presente en tensión entre la decadencia de la hegemonía neoliberal, y la naturalización de una "prolongada crisis del sindicalismo".

Esta concepción sobre la naturalización de una crisis sindical, se destaca por el ejercicio de narrar al sindicalismo sin entender la dinámica contradictoria entre "la tradición" y "la historia". De acuerdo con Benjamin, esta dinámica entre "la historia" y "la tradición" radica en que mientras "la historia es el tiempo homogéneo de la clase dominante, la tradición pertenece a los oprimidos y explotados que, al contrario que la clase dominante, saben que los estados de emergencia no suponen la excepción, sino la regla" (Eagleton; 1998: 82-83; Benjamin, 2007: 257), y que por lo mismo involucran para los oprimidos y explotados una diversa forma de integrar y reconocer(se) en el pasado.

Por ello, la relación dinámica y contradictoria que Benjamin nota entre historia y tradición, involucra el hecho de que "en cada época hay que hacer de nuevo el intento de arrebatarle la tradición a un conformismo que está a punto de dominarla" (2007: 255), y es más bien este el aspecto que centramos en nuestra crítica, en referencia a la concepción "tradicional" del sindicalismo, ya que esta acomodación sujeta y neutraliza la conflictividad del pasado, mirando desde el prisma ideológico del "consenso" que han instalado las clases dirigentes (Agacino, 1994) y ha reproducido la intelectualidad orgánica de la "transición democrática", como parte de un relato sobre "un tiempo homogéneo".

De esta acomodación es que, por ejemplo, la remembranza del sindicalismo en un periodo tan denso, tenso y conflictivo como la Unidad Popular (1970-1973), asuma un carácter nostálgico y melancólico, lo que involucra la ausencia de un cuestionamiento crítico sobre el proceso que llevó al golpe de Estado, y/o como evocación de un presente a redimir, enfocándose en el carácter de las fuerzas golpistas que habitaban el seno del sindicalismo de la época y sus consecuencias para el movimiento de trabajadores, en términos de derechos laborales y políticos.

En estos términos nos enfrentamos a la pérdida del significado inmanente y práctico de la lucha de clases. Para Eagleton (1998: 45) "el significado inmanente que se retira del objeto bajo la mirada paralizante de la melancolía lo deja como un puro

\footnotetext{
${ }^{7}$ Tomamos aquí la noción de "intelectualidad orgánica" de Gramsci (1984: 10-12), como "una o varias capas de intelectuales" que como productos de un grupo social, "le proporcionan su homogeneidad y la conciencia de su propia función no sólo en el terreno económico, sino igualmente en el terreno social y político". Gramsci, dice que estos pueden entrar en conflicto con la misma clase que los dirige, y superpone el debate entre "intelectualidad orgánica" e "intelectualidad tradicional", como una apertura en la historia.
} 
significante, una runa o un fragmento recuperado de las garras de un sentido unívoco y rendido incondicionalmente al poder de quien formula la alegoría”. Este retiro involucra un desplazamiento hacia la significación impotente de los sujetos (Julián, 2013b), ante el ejercicio metonímico al que recurre la ideología en la conformación desencadenada de significados, como parte del (re)ordenamiento simbólico de alegoría intelectual rememorativa, que deja al sindicalismo en "la incapacidad de proyectar un significado por sí mismo" (Jameson, 1972: 60).

Este (re)ordenamiento simbólico con el que se encuentra la "excavación histórica" (en el presente), identifica la desolación en la que sigue varado el sindicalismo, sin poder superar la condición de "pérdida" y de un presente sacrificado ${ }^{8}$, en donde incluso los esfuerzos por "el rescate sin cesar del pasado", se realizan desde la posición de comodidad y conformidad de desplazamiento del significado inmanente, cayendo a la vez, en esta incesante búsqueda de identidad e incomplitud (con el pasado), en la telarańa narrativa que se adecua al proceso de racionalización, generado por la historiografía sindical, que enfoca su esfuerzo en: a) establecer una sincronía-lógica entre la actualidad de las asimétricas relaciones laborales y las coaliciones de poder de las clases dominantes en su correspondencia con las dirigencias e intereses sindicales (Julián, 2012b), y b) modelar y promover un significado del sindicato que ha expulsado la lucha de clases como proceso de rememoración y de la tradición, con orientación a obtener reformas laborales y acuerdos corporativos.

A este uso de la tradición, como herramienta de la clase dominante (Benjamin, 2007: 255), Benjamin contrapondrá la estrategia "de canalizar el deseo tanto desde el presente como desde el pasado hacia el futuro: de detectar en el declive del aura la forma de nuevas relaciones sociales y libidinales, realizables mediante la práctica revolucionaria" (Eagleton, 1998: 75). Como parte de una soterrada crítica ideológica, esta demanda envuelve una profunda dialéctica que dinamita la continuidad de la historia, y exhorta los linajes reprimidos de la tradición, como "un filamento entre muchos otros que hay que convertir en uno de mayor importancia por medio de la práctica político-cultural" (Eagleton, 1998: 93).

De seguro ésta disquisición, entre una obstinada dictadura (Moulián, 2001), una obsesiva remembranza y un paradigma socio-histórico racionalizador de interpretación de la realidad sindical, conectan como una triada de disposiciones subjetivas para analizar el legado dictatorial. En éste legado, el sindicalismo no puede estar exento, lo que le empuja permanentemente a verse a sí mismo, como un producto de un presente que contiene al pasado, ya que "la memoria forja la cadena de la tradición de eventos pasados de generación en generación” (Benjamin, citado en Jameson, 1972: 62). Es por esto que la reconstrucción histórica de una temporalidad como linealidad, no recoge eminentemente la matriz del problema, y se enfoca en situaciones, coyunturas, etc., como parte de una regresión que trata de reordenar, artificialmente y de forma explicativo causal, la situación presente, promoviendo procesos de identificación en "la culpa(bilidad)", en cuanto

\footnotetext{
${ }^{8}$ Eagleton señala que "la lucha por el pasado oprimido" es fructíferamente ambigua: una lucha en su nombre (Benjamin advierte que ni los muertos estarán a salvo si éste triunfa) que puede llevarse a cabo sólo rescatando sin cesar el pasado, haciendo que las sombras de los muertos se congreguen sobre el hoyo vacío de un presente sacrificado" (Eagleton, 1998: 86).
} 
subjetivación que reniega del pasado en términos de la suspensión negativa de la tradición, y "la victimización", como objetualización del sujeto en el campo de fuerzas sociales, los cuales constituyen elementos centrales de estas narrativas.

Desde el punto de vista teórico Benjamin "desconfiaba de la narrativa como tal (el continuo histórico o "progreso") y estaba fervientemente comprometido con el programa ilustrado de resolución del mito"... con "su idea de que para liberarse de él se debe atravesar completamente el mito" (Jameson, 2011: 44).

Debemos clarificar que Benjamin entenderá por "el mito", en tanto factor de producción de experiencia y de reproducción social, en tanto "creencia en la primacía ontológica de un código específico, la escala que desciende desde la historia y lo político a la ley natural a las formas del ser" (Jameson, 2011: 44). Es por ello que esta naturalización, a la vez requerirá, para Benjamin, una estrategia de desmitificación centrada en "atravesar completamente el mito", como respuesta política a su "profundidad"9.

El mito contiene una tensión dialéctica (Jameson, 1972: 54). La relación de acomodación entre "historia" y "tradición" y su simbolización involucra una lógica de saturación para promoción del olvido desde la clase dominante, con la institución del mito, así como una rememoración racionalizada y ritual. De acuerdo con ello, la desmitificación aparece para Eagleton (1998: 47) como un espacio de redención del sujeto frente a la ritualidad y "el placebo" del mito, al constatar que "liberado de las tiranías ideológicas de la naturaleza, el sujeto no puede encontrar consuelo en el mito compensatorio de la historia, porque éste también se ha reducido a una mera repetición ritual”, y esta repetición es parte de su carácter sintomático (Jameson, 1972; 1988), la cual nos obliga "a leer estos objetos simbólicos a la segunda potencia: no directamente para descifrar uno-a-uno el sentido de ellos", sino que en "el sentido de que cada hecho del simbolismo es en sí sintomático" (Jameson, 1972: 57).

Lo que podemos constatar es que este simbolismo consta de una actividad práctica de (re) "nombrar" y de clasificar todo hecho, continuando su repetición ritual, en un orden secuencial y coherente. Esta es la lógica del tabú racionalizador que en el caso de la construcción de un relato de "victimización del sindicalismo", propone selectivamente no desentrańa su lógica adaptativa, y las estrategias de movilización social y métodos de protesta que desarrolló en dictadura, sino que lo prefigura como un objeto-del-poder (dictatorial y económico). A continuación ofrecemos una posibilidad teórica para "redimir" y "liberar" la actividad del sindicalismo como sujeto de sus constricciones, y no tan sólo como un artefacto obsoleto y purificado de su acción, decisión y poder, por el ejercicio intelectual de "la remembranza obsesiva" y los mitos respecto al sindicalismo desde el espacio de "la tradición”.

\footnotetext{
${ }^{9}$ Es interesante el paralelo que puede realizarse entre la visión del mito en Benjamin (2007) y la propuesta lacaniana del concepto de fantasía, expuesto por Zizek (2010: 73) en cuanto a la capacidad de "la fantasía como soporte de la realidad", y a la estrategia política de "atravesar la fantasía". Ambas pueden ser vistas como políticas y definiciones de la ideología, en cuanto a desentrańa la profundidad del fenómeno del poder (Jameson, 1988). Por cuestiones de espacio omitimos este tema, que de todas formas alienta nuestras reflexiones en el análisis del espacio del trabajo y la (no)constitución de identidad(es) (Julián, 2013b).
} 


\section{REMEMBRAR EL SINDICALISMO EN DICTADURA DESDE LA UNIDAD POPULAR}

Referente a la particularidad del sindicalismo en el presente, podemos decir que se encuentra sujeto a "la emergencia de "nuevos" fenómenos, identidades, espacios de trabajo y empleo, "nuevas" relaciones inter-trabajadores/as, y actores/movimientos sociales, etc.", los cuales, conjuntamente, dan "origen a un proceso de resquebrajamiento de las cristalizadas relaciones de poder que articulaban la práctica del sindicalismo en el país” (Julián, 2012a: 96).

La lenta descomposición y tensiones del proyecto unitario sindical (neo)corporativo de la CUT, sumado a sus dificultades para posicionarse como sujeto político en materia de restablecimiento y expansión de los derechos laborales, han movilizado la resignificación del pasado y las búsquedas de una "re-unificación a las tensiones" en el seno sindical. El aporte de la crítica de Benjamin a esta actual situación, en referencia a la tradición y su importancia, es precisamente "la explosión que destroza el impulso regresivo de recuperar una unidad perdida, dislocando el continuo imaginario entre el pasado y el presente con la figura simbólica del cadáver; pero (es) precisamente a través de esta irrupción de la diferencia que el pasado da un giro de $90^{\circ}$ para el hablar al presente, como advertencia de que el presente no debe repetirlo compulsivamente" (Eagleton, 1998: 97).

De esta forma la exhumación del cadáver puede ser una nueva estrategia que restituye de presente el pasado. Pero ¿el cadáver de quién? Nuestra respuesta está en la materialidad de las relaciones de la "lucha de lo oprimido" que han llevado en los últimos tres años (2011-2013) a la exhumación del cadáver de cuatro iconos de la política pregolpista: Eduardo Frei-Montalva, Salvador Allende, Víctor Jara y Pablo Neruda. En este contexto la exhumación puede ser entendida como la acción conjunta de: a) "fuentes ilustradas" de búsqueda de la verdad sobre el mito que rodea la muerte; b) como la reivindicación alegórica de mártires que sufren su pasión en la encarnación de la melancolía (Jameson, 1972: 59), y/o como c) objetos que están sujetos a la pérdida del "significante inmanente” y a ser alegorizados en su preservación por la eternidad (Jameson, 1972: 60).

La continuidad del pasado en el presente, en un sentido hegeliano de la exhumación ${ }^{10}$, es la que impulsa la advertencia al sindicalismo sobre "la repetición compulsiva" de su pasado, mientras que los eslabones de permanencia y cambios postdictatoriales han forzado la exhibición del cadáver de Salvador Allende y del ("legado" del) gobierno de la Unidad Popular ${ }^{11}$, los cuales pueden ayudarnos a encontrar las primeras contradicciones de la tradición que llaman a desmitificar una historia del sindicalismo en la dictadura ${ }^{12}$ como un sujeto homogéneo e idéntico a sí mismo ${ }^{13}$.

\footnotetext{
${ }^{10}$ Quizás en este punto nos separamos de la visión de Jameson sobre el no-hegelianismo de la noción de temporalidad de Benjamin (Jameson, 2011: 47), y más bien su reivindicación a la "dialéctica espacial postmoderna que tanta gente (muy particularmente Henri Lefebvre) ha reclamado en oposición a la temporal hegeliana".

${ }^{11}$ Como en el caso de la latencia de los cadáveres caminantes (Walking Dead), y una política de la remembranza (Ricoeur, 2002) en su incomplitud con el pasado (Jameson, 2011: 46). Este es un proyecto de largo alcance en el que me encuentro trabajando en la actualidad, referido al campo político y del trabajo.

${ }^{12}$ Por temas de espacio acotamos esta revisión a algunos hitos que pueden resaltar nuestra propuesta teórica.

${ }^{13}$ Esta propuesta a la vez va acompańada del sobreseimiento el día 24 de junio de 2013 de la investigación de la muerte del ex presidente el 11 de septiembre de 1973 en el Palacio de la Moneda. La Corte de Apelaciones de Santiago determinó como causa de muerte el suicidio.
} 
Referente al gobierno de la Unidad Popular, es común encontrar la evocación de una clase trabajadora movilizada, homogénea y revolucionaria. Contrario a ello, el período de la Unidad Popular no sólo contó con un sindicalismo como sujeto de la vía chilena al socialismo $^{14}$, la cual es parte de uno de principales aspectos que incita la rememoración del paraiso perdido de la clase trabajadora, sino que también encontró en su seno diversas oposiciones, resistencias y tensiones al proceso político en curso (Drake, 1996).

Un caso destacable que puede ayudarnos a problematizar esta suerte de "unidad sindical memórica", es la del caso de la formación e identificación de la "aristocracia obrera" ${ }^{15}$ en el sector de la minería del cobre, en medio del proceso de nacionalización de la industria. Las huelgas obreras del año 1971 y 1973 en el sector, mostraban la débil adhesión al programa de la UP, el "desclasamiento" (como propuesta de identificación sociopolítica), la persistencia de la lógica económica y del sostenimiento difícilmente negociable de los privilegios adquiridos por un sector de la clase trabajadora que contaba con un poder estructural de presión y negociación incomparable a nivel nacional ${ }^{16}$.

Si esta fuese la dirección que debiese orientar el análisis (destacar estas contradicciones en el seno de "la unidad" como explosión a la coherencia narrativa) ¿ Sería posible hablar del mito de "Un" sindicalismo como sujeto/objeto homogéneo dentro de aquellas narrativas? Creemos que, si bien es necesario soterrar el "mesianismo esencialista" de la lucha por lo oprimido en el pasado, también es necesario enfrentarse a la heterogeneidad de los tabús racionalizadores de la experiencia sindical en dictadura, los cuales constituyen una estrategia y práctica reconstructiva de "una estructura que traducimos a términos contemporáneos, dejando atrás una narrativa periódica que ya no podemos tolerar y que debe ser reprimida e ignorada", lo que implica que "si existe el texto antiguo es para ser revivido sin demasiada culpa ni auto-recriminación intelectual" (Jameson, 2011: 47).

Por ello, es que habría que desmitificar la idea de "una crisis del sindicalismo" (Zapata, 2003), atravesando la heterogénea composición que portaba el sindicalismo en dicha época, y liberando las fuerzas que fueron contenidas en el seno de la narrativa que las articuló como "unificadas" para desentrañar los límites prácticos de su acción en presente.

En el caso de la permanente evocación del pasado y la "represión de narrativas" (Jameson, 2011: 47), la desmitificación del sindicalismo cobra permanencia en el diagnóstico de Frank Gaudichard (2003: 21), el cual señala que "la actual realidad del sindicalismo está claramente marcada por la dictadura que destruyó por completo el movimiento sindical, pero también por el modo en que se desarrolló la "transición democrática”... bajo el pretexto, legítimo y necesario, de combatir a la dictadura dejaron a un lado la discusión sobre las causas y responsabilidades en el seno de la izquierda de la derrota de 1973 ".

\footnotetext{
${ }^{14}$ Con respecto a este posicionamiento pueden ser vistas las resoluciones del Congreso de la CUT de 1971 que llaman a generar nuevos organismos unitarios en la base y en el ámbito local. Resoluciones de la novena conferencia nacional, documento de estudio y trabajo para las organizaciones sindicales y sus dirigentes del país, CUT.

${ }^{15}$ Allende, llamaría "aristocracia obrera" a los trabajadores del Cobre en su discurso del primero de Mayo de 1971, debido a una huelga en Chuquicamata de parte de sus trabajadores, la cual fue conjurada por la burocracia y disciplina del partido comunista, a través del presidente interino de la CUT, Víctor Díaz.

${ }^{16}$ Creemos que este tema cobra gran importancia y relevancia en el presente desde las movilizaciones de trabajadores del cobre y las diversas identidades políticas convergentes en el paro nacional de advertencia de los trabajadores y trabajadoras cobre el día 9 de abril y 26 de junio.
} 
La mirada de Gaudichaud pone en el lugar de la crítica el mismo sindicalismo que había sido puesto en el centro de la "nostalgia allendista", y lo moviliza hacia el proceso de "transición democrática". El tabú racionalizador no se pronuncia sobre las causas del golpe militar y su éxito, las cuales siguen siendo objeto de expulsión en la rememoración, como concepción de un pasado de decadencia y derrota, lo cual está de la mano del retiro del significante en/de la lucha de clases, con la intención de componer y justificar el ejercicio lógico entre la evocación de la "unidad pérdida" (del paraiso allendista) y la nuevas tácticas de "renovación del clasismo sindical" por las lógicas tripartistas en las relaciones laborales ${ }^{17}$. Ello involucra una sistemática repetición del mito de la "unidad" (sindical) y un naturalizado olvido que ha decidido, por ejemplo, no rememorar las estrategias golpistas del sindicalismo demócrata cristiano, la formación de una "aristocracia obrera" y su continuidad, la formación de cuadros dirigentes golpistas en EEUU durante los años 60', los problemas de democratización en el seno de la CUT ${ }^{18}$, y los acuerdos de un sindicalismo golpista con la dictadura militar en los primeros 3 años de gobierno, como parte de la complejidad interna (del sindicalismo) en su selectiva y tecnológica readecuación a los modelos de tortura, persecución y desaparición.

Retomando ahora la advertencia a la continuidad (Eagleton, 1998: 97), creemos que la no-desaparición del sindicalismo en el periodo constituye un foco sintético a problematizar, pues esta exhibe la presencia del pasado en el presente de una forma particular. A modo de ejemplo podemos citar a Paul Drake (1996: 130) quien muestra una táctica de mimetismo, entre la "reconversión política" de las tendencias clasistas-marxistas del sindicalismo, y un "matrimonio por conveniencia" entre éstas y la democracia cristiana (DC), a modo de no sufrir mayor persecución por la dictadura militar, la cual "había ganado el apoyo de sindicatos anti-allendistas, y grupos de trabajadores de cuello blanco, como por ejemplo, conductores de camión, empleados del sector bancario y trabajadores del cobre".

La no-desaparición presenta una dualidad al interior del sindicalismo. Por una parte, constituye una mimesis que invisibiliza las contradicciones en su seno, pero por otra parte, la no-desaparición es el resultado de un movimiento adaptativo incesante, el cual le permitió al sindicalismo en un segundo momento, y en un contexto profundamente adverso, desplegar sus recursos y su limitado poder organizacional disponible, trascendiendo el espacio de trabajo, retomando las lógicas locales e ilegales de coordinación y movilización. Esta "otra cara" de la no-desaparición se desarrolla pese a la lógica institucionalizada de descentralización al nivel de empresas de la negociación colectiva y de la organización de

\footnotetext{
${ }^{17}$ Aquí podemos observar que el tabú racionalizador opera como una filosofía de la historia, en tanto "la filosofía de una época histórica no es pues otra cosa que 'la historia' de aquella, no es otra cosa que la masa de variaciones que la clase dirigente ha logrado determinar en la realidad precedente: historia y filosofía son inescindibles en este sentido, formando un 'bloque"' (Gramsci, citado en Santucci, 2005: 81), el cual opera como ideología históricamente orgánica (Gramsci, citado en Santucci, 2005: 83), es decir, teniendo "una validez que es validez 'psicológica', 'organizan' las masas humanas, forman el terreno en el cual los hombres se mueven, adquieren conciencia de su posición, luchan, etc.", en función de los objetivos de la clase dirigente.

${ }^{18}$ Gaudichaud, Frank (2003: 11) se refiere especialmente al tema de las elecciones de 1972, que exhiben "que la unidad de la CUT es solo una fachada”. Donde, a partir de la abstención de 560.000 trabajadores y trabajadoras de participar en las elecciones, se podía deducir que "la CUT no representa para ellos un compromiso de lucha esencial en el contexto de un Chile inmerso en una agitación socio-política, sin precedente histórico”.
} 
los sindicatos (Espinoza y Yanes, 1998), sobrellevando tensamente la mimesis, y logrando agrupar a más actores sociales a su alrededor, como eje de convergencia de los sectores populares en las primeras convocatorias de las Jornadas de Protesta Popular (Salazar y Pinto, 1999). Las consignas de movilización que lograron la adhesión de otros actores del mundo popular, implicaban la confluencia de demandas referidas a la institucionalidad laboral con la política en materia de derechos ciudadanos y sociales, las cuales estaban estrechamente entrelazadas con el carácter del régimen dictatorial (Zapata, 1992; 2004), y que permitían la rápida adhesión a las convocatorias desde el mundo sindical y social ${ }^{19}$.

Lo que se trasluce de estos hechos, es el rol del sindicalismo, movilizándose más allá del espacio y el proceso de trabajo, y activando su posicionamiento en la política nacional, en la cual juega un rol estratégico entre: a) sobrevivir al proceso de neoliberalización, y generar las condiciones para su propia continuidad, reproducción y desarrollo; y b) avanzar en el proceso de restablecimiento de la democracia (Touraine, 1989; Drake, 1996; 2003).

En sentido contrario, la intelectualidad orgánica de la "transición democrática", como parte de una narrativa mono-causal con el fin de justificar las dificultades del sindicalismo para desarrollar una mayor adaptabilidad, innovación, diversificación de tácticas/estrategias de negociación y fortalecimiento de su acción colectiva ${ }^{20}$, insistirá en la permanencia y trascendencia de la mónada dictatorial, lo cual sienta un proceso retrospectivo objetualizado, y no introspectivo crítico, que de cuenta de la subjetivación de la tendencia de domesticación tortuosa de los discursos y de la tradición en la praxis sindical ${ }^{21}$.

Este fenómeno puede ser destacado a partir de lo que seńala Campero (2000: 6), al referirse al sindicalismo, destacando que "su potencial poder estratégico de presión no pudo ser ejercido con suficiente éxito en la situación del autoritarismo que vivía el país en el período", lo que sin embargo, y paradójicamente, permitió una innovación en las estrategias sindicales, que pueden ser observadas en su vinculación con organizaciones no-gubernamentales, la cooperación con instituciones sociales y civiles, y la estrategia de internacionalización de sus demandas y problemáticas, las cuales pasan a ser principios articuladores que movilizan la acción del presente de un sector del sindicalismo, luego de años de negación de este flujo organizativo y táctico, hacia la convergencia con los movimientos sociales y organizaciones de la "sociedad civil" (Julián, 2012a).

A la vez, para sostener el vínculo entre este pasado y el presente del sindicalismo, es necesario reconocer que el sindicalismo ha estado aliado estratégicamente a los partidos políticos de forma subordinada durante gran parte de su historia ${ }^{22}$. En el periodo de la

\footnotetext{
${ }^{19}$ También se puede mencionar que la no-desaparición convivía con la latencia de las políticas de la desaparición montadas por la dictadura militar. De allí que en otros trabajos pensemos en exhumar los cadáveres de dirigentes sindicales asesinados en dictadura, tales como Victor Díaz (1976) y Tucapel Jiménez (1982), de forma de entender el contradictorio proceso de la sobrevivencia sindical.

${ }^{20}$ Lo cual recién comienza a diluirse con una continuidad de la tradición clasista en nuevos liderazgos sindicales (Julián, 2012a).

${ }^{21}$ Con "tortuoso" claramente nos referimos a las disposiciones coercitivas que instauró el régimen militar como las prácticas de tortura que pueden ser entendidas como "un conjunto de técnicas diseñadas para colocar al prisionero en un estado de profunda desorientación y shock, con el fin de obligarlo a hacer concesiones contra su voluntad” (Klein, 2007: 23).

${ }^{22}$ Podríamos decir lo contrario del origen de la relación sindicalismo y partidos en el caso del partido comunista, el cual más bien se forjó en el núcleo de los conflictos obreros en el seno de la clase trabajadora. Aún así este hecho no impidió un cambio en el pasar de las décadas con la predominancia de las orientaciones estalinistas al interior del partido.
} 
dictadura militar, esta alianza estuvo marcada por: a) la demanda de un cambio a nivel del régimen político; y b) la composición de los dirigentes de las principales organizaciones sindicales de la época (Díaz y Noé, 1984; Arrieta, 2003; Ulloa, 2003; Frías, 2008), lo cual habla de un núcleo de cooperación que articuló un modelo de continuidad, el cual está intrínsecamente asociado a la relación de subordinación sindical a las líneas partidarias ${ }^{23}$, y la tarea de ser "la cadena de transmisión de los partidos" políticos a la clase trabajadora organizada (Gaudichaud, 2003: 3). Así también destaca la arquitectura de los modelos de negociación e "institucionalización democrática" del proceso de transición (Zapata, 1992; Julián, 2012b), el vuelco electoral de las protestas sociales (Paredes, 2011), con la correspondiente pérdida de autonomía del movimiento sindical, y la gestación de un modelo neocorporativo de relaciones laborales con la política de los acuerdos marcos (Falabella y Fraile, 2010), lo que finalmente dejará pendiente las reformas laborales requeridas, como programa de acción, por el movimiento sindical en dictadura en materia de, por ejemplo, huelga y negociación colectiva (Zapata, 1992; Nuñez y Aravena, 2011).

Este proceso de simbiosis se produce entre los partidos políticos y un heterogéneo movimiento sindical que: a) en su vertiente clasista había asumido la "renovación del socialismo" y era derrotado en la dirección de la CUT en 1988 (Drake, 1996), y b) en su anterior vertiente golpista, había reintroducido su concepción democrática en busca de acuerdos y compromisos de bienestar-social. Así se sincronizan sus nuevos discursos y estrategias (Drake, 2003: 148-158), en el nudo de "la transición" pasando a articular un nuevo concepto de "unidad" sindical, basado en la adecuación de la tradición (clasista) a la visión de la historia (triunfante) luego del golpe militar.

De allí es que en esta traición a la tradición en el pasado, encontremos los rastros de la evocación a un mito superpuesto en el presente, articulada a modo de necesidad programática del consenso, que se reitera por la demanda de democracia y de democratización, por medio de las elecciones presidenciales y parlamentarias en noviembre próximo (2013), y la apertura de los sindicatos y la dirigencia de la CUT a un nuevo acuerdo corporativo con el bloque concertacionista, post-crisis del modelo neocorporativo en el último gobierno.

La pregunta que se desprende es: ¿No fue acaso esta la receta que articuló la narrativa de la Concertación como proyecto estratégico de disciplinamiento sindical durante 20 años? Esta pregunta puede entenderse sólo en la "persistencia del presente", en cuanto lugar y espacio del ejercicio de recordar, y en cuanto lugar en donde se encuentran aún planteados la tarea de instituir los cambios necesarios en materia laboral, que parecen haber quedado "pendientes" en el movimiento "transicional" (Zapata, 1992; Nuñez y Aravena, 2011), tanto como "déficit y deuda democrática" (Paredes, 2011), como parte

\footnotetext{
${ }^{23}$ Seńalaba Díaz y Noé (1984: 31) que en la lucha contra el autoritarismo de la dictadura militar, y para la recuperación de la democracia estable era necesaria la "la concertación social y política, de todos los sectores perjudicados por las políticas de autoritarismo", que los dirigentes sindicales parecían estar de acuerdo con dicha proposición, sin antes reconocer el rol de vanguardia del sindicalismo en la defensa de los intereses de los trabajadores. Sin embargo llaman la atención sobre un punto central para la época: "estos llamados a la concertación pueden envolver una nueva manera de postergar injustamente la satisfacción de los intereses de los trabajadores (y trabajadoras) y de los sectores populares, en beneficio de sectores siempre privilegiados bajo los regímenes capitalistas que han existido y existen en nuestros países". Una clara voz profética de "la transición".
} 
del desnudo de la ideología neoliberal dominante (Julián, 2013a), lo que problematiza la estrategia corporativa del sindicalismo y la profundidad de su "crisis" en la actualidad, cuando se encuentra ad portas de la repetición y re-emergencia de diversos desafíos en su núcleo (Julián, 2012a), los cuales difícilmente la "unidad" regresiva podrá solucionar, sin sentar un nuevo nivel de acomodación entre "la tradición" y "la historia" por medio del ejercicio las clases dirigentes y la intelectualidad orgánica de la "transición": los orígenes de la construcción de un nuevo mito y fantasía.

Por otra parte, "el recuerdo", como escape del presente (domesticado y cerrado), parece localizar en su evocación de la dictadura, un elemento ideológico funcional a los intereses de las clases dirigentes, como momento constituyente, referente y aglutinante, en términos de cohesión identitaria, de un fragmentado, débil y disciplinado sindicalismo (Julián, 2012b), lo cual no deja de constituir una paradoja del sindicalismo chileno, al seguir sosteniendo la dictadura como la base de la construcción narrativa de un nuevo ejercicio de subordinación de su acción.

\section{CONCLUSIONES}

Lo que hemos intentado exponer en éste artículo ha estado atravesado por el objetivo de dar mayor complejidad del tratamiento mitológico del sindicalismo, "como víctima", lo que hace necesario repensar la búsqueda por la tradición y el pasado oprimido, ante la construcción narrativa de una intelectualidad que, orientada por una promoción de la actividad sindical desde el tabú racionalizador de la "transición democrática", que primero, no renuncia a una idolatría idealista del "trabajador" con un cierto esteriotipo arquetípico ceñido en una nostalgia icónica-distante del sindicalismo de tradición clasista ${ }^{24}$, y que segundo, ha formulado una justificación ideológica del actuar de la dirigencia sindical con una orientación neo-corporativa, como cristalización práctica de acomodación entre "la tradición" y "la historia", apelando a un rescate fragmentario y arqueológico selectivo de la historia sindical, lo cual ha asumido una naturalización trágica a nivel narrativo (Jameson, 2011: 44) con el fin de inmovilizar la activación y/o nuevos modelos de organizaciónacción. Finalmente, esta tendencia ha sido acompañada del sobre-dimensionamiento de los cambios productivos, los cuales si bien constituyen un foco del debilitamiento del "poder estructural” del sindicalismo, también encuentran la dialéctica de visibilizar e invisibilizar las características y las potenciales bases reconstructivas que anidan las mismas transformaciones, como la formación de un precariado y la nueva morfología de la clase trabajadora (Julián, 2013b).

Estas tres intersecciones de la narrativa de la "transición democrática" plasman la angustiante "melancolía por el sujeto" en el mundo del trabajo, la cual llama a inmovilizar, tanto la reorganización memórica activa del sindicalismo (Benjamin, 2007: 260), como un posicionamiento en "la memoria" que aliente un proceso de recuperación del aprendizaje colectivo de "la tradición", en torno a las experiencias de resistencia, tensión

\footnotetext{
${ }^{24}$ En éste sentido y para una ampliación de este enfoque, se hace atingente el debate planteado por Enrique De la Garza (2011; 2012) en referencia a los "trabajos no clásicos", que más bien estarían acompañados de una relación entre sujetos y significados diversos, y no estandarizados bajo la teoría clásica del asalariado, lo cual problematiza la estructura sindical, y la búsqueda de "unidad", en términos de elaboración de contenidos identificatorios para la toda la clase trabajadora (Julián, 2013b).
} 
y movilización desarrolladas por la confluencia de un heterogéneo núcleo sindical, y los sectores populares en la dictadura militar en Chile (Salazar, 2003), con el objetivo de reinstituir al sindicalismo, en presente, como sujeto socio-político, volviendo la mirada hacia la tradición, la cual interroga su pasado, como parte de un ejercicio de profanación de la historia por los dominados y, por medio del ejercicio crítico de la violencia sobre sí mismo (Benjamin, 2007).

Debemos clarificar que en nuestra mirada a "la tradición" no se esconde un esencialismo mesiánico (Benjamin, 2007: 265), ya que "la tradición no es otra cosa que una serie de espasmos o crisis dentro de la historia de clases misma, un determinado conjunto de articulaciones de esa historia, no las letras de una palabra invisible" (Eagleton, 1998: 83), de allí que se interpela nuevamente a el pasado con el objetivo de indagar en las relaciones entre las clases sociales y el sindicalismo, descartando "el mal del coleccionista", he reintroduciendo los significados que el tiempo ha incrustado en él (Benjamin, 1989), los cuales constituyen su "pasar" en su-presente, desde una configuración concreta, problematizando la heterogeneidad de las respuestas y la diversificación de estrategias del sindicalismo, en cuanto actor (social) en estos procesos, de forma de generar una mayor complejidad y espacio a la generación de resistencias y el fortalecimiento colectivo de las organizaciones sindicales, blindándose, a la vez, de la introducción de una visión fetichista y abstracta del "sindicato", como sujeto trascendente y "utópico" de la sociedad de clases, pero conservando un pasado donde el sindicalismo poseía una clara "legitimidad como canal de expresión del mundo popular” (Salazar y Pinto, 1999: 122),

Así es como creemos que la relación visibilizada por Benjamin entre "historia" y "tradición" exige un profundo giro de los enfoques sobre sindicatos y sindicalismo, conjunto a un ejercicio investigativo científico con capacidad de reflexividad frente a las narrativas homogéneas y planas de la historia (Jameson, 1972), asumiendo como tarea el problematizar el espacio de acomodación que asume la tradición descansando a la sazón de la historia (sin auto-crítica e interpelaciones a la continuidad y la tragedia de la mónada dictatorial), donde la remembranza se vuelve un ejercicio justificatorio de la inmovilidad y la inactividad, y donde sólo la violencia de la exhumación del cadáver parece restituir la rememoración a la atadura constrictiva del olvido.

Para superar esta atadura, creemos que sería atingente considerar la propuesta de Benjamin, la cual a "modo de terapia colectiva, por no decir una revolución cultural", constituye un "trabajo sistemático y, sin embargo, una reexperiencia... la cual, como en Freud, por medio de la completud de sus compromisos con el pasado, permite ahora que el pasado sea por fin dejado atrás y resulte olvidado de un modo más pleno (los muertos sepultando finalmente a sus muertos)" (Jameson, 2011: 46).

Esta forma de atravesar el mito nos coloca en la encrucijada por desentrañar los elementos de la transición y su narrativa, como las características de su funcionalidad hasta el día de hoy, con el objetivo de sentar y redimir las nuevas estrategias y tácticas que asumirá el sindicalismo, tanto en problematizar su unidad y su futuro, como en cuanto a generar perspectivas para la continuidad de "la tradición", en el cumplimiento de "los compromisos del pasado", (Paredes, 2011), y el imperativo de su desacomodo de "la historia" como estrategia inadaptada de no-desaparición. 


\section{REFERENCIAS}

Agacino, Rafael. Acumulación, distribución y Consensos en Chile. Versión on-line disponible en ARCHIVO CHILE. Centro de Estudios Miguel Enríquez (CEME), 1994.

Aguiar, Santiago. Rastros de los Sindicatos y la Clase Obrera bajo la dictadura. Relación social de explotación: estructura, sujeto y acción social. Serie Apuntes de Estudios del Trabajo. ISSN 0718-5413. Santiago de Chile, 2008.

Aravena, Antonio y Nuñez, Daniel. "Los gobiernos de la Concertación y el sindicalismo en Chile”, Revista Trabajo 5/8 (2011): 113-130.

Arrieta, Adolfo. Mercado de trabajo, organización, representación sindical y gremial. Santiago de Chile: Oficina Internacional del Trabajo, 2003.

Benjamin, Walter. Discursos interrumpidos I. Buenos Aires: Taurus, 1989.

Illuminatios. New York: Schocken Books, 2007.

Campero, Guillermo y Valenzuela, José A. El movimiento sindical chileno en el capitalismo autoritario, 1973-1981. Santiago de Chile: ILET-AHC-PET, 1981.

Campero, Guillermo. "Respuestas del Sindicalismo ante la Mundialización: El caso de Chile”. Instituto internacional de estudios laborales. Ginebra, Suiza: Organización Internacional del Trabajo (OIT), 2000.

De la Garza, Enrique. "Problemas clásicos y actuales de la crisis del trabajo". En Enrique de la Garza y Julio César Neffa (Comps.), El futuro del trabajo - el trabajo del futuro. Buenos Aires: Consejo Latinoamericano de Ciencias Sociales, (2001): 11-32.

Díaz, Eugenio y Noé, Marcela. "Partidos Políticos y sindicatos: ¿Competencia o solidaridad?", Revista Nueva Sociedad 74 (1984): 26-34.

Drake, Paul W. (1996). Labor movements and dictatorships: The Southern Cone in comparative perspective. Baltimore; London: Johns Hopkins University Press.

"El movimiento obrero en Chile: De la Unidad Popular a la Concertación", Revista de Ciencia Política XXIII/2 (2003): 148-158.

Eagleton, Terry. Walter Benjamin. Hacia una crítica revolucionaria. Madrid: Cátedra, 1998.

Espinoza, Malva y Yanes, Hugo. Sindicalismo en Chile: Un actor que sobrevive contra viento y marea. Temas Laborales $N^{o}$ 8. Santiago de Chile: División de Estudios de la Dirección del Trabajo, 1998. 
Falabella, Gonzalo y Fraile, Lydia. "Tripartism and Economic Reforms in Uruguay and Chile”. En Lydia Fraile (Ed.), Blunting neoliberalism: Tripartism and economic reforms in the developing world. New York: Geneva: Palgrave, Macmillan, (2010): 128-175.

Frías, Patricio. Desafíos del sindicalismo en los inicios del Siglo XXI. Buenos Aires: Consejo Latinoamericano de Ciencias Sociales, 2008.

Garretón, Manuel Antonio. "The socio-political matrix and economic development in Chile”. Discussion Paper Series Number Fifteen A. Manchester: IPPG Programme Office, School of Environment and Development, University of Manchester, 2007.

Gaudichaud, Frank. "La Central Única de Trabajadores, las luchas obreras y los Cordones Industriales en el período de la Unidad Popular en Chile (1970-1973)", Análisis crítico y perspectiva. Santiago de Chile, 2003.

Jameson, Fredric. Marxism and Form; Twentieth-Century Dialectical Theories of Literature. Princeton, N.J.: Princeton University Press, 1972.

The Ideologies of Theory: Essays 1971-1986. Theory and History of Literature. 2 vols. Minneapolis: University of Minnesota Press., 1988.

."Walter Benjamin. Constelaciones", Revista Minerva 17 (2011): 39- 48.

Julián, Dasten. "Tendencias de un sindicalismo fracturado. Sindicalismo autoritario v/s sindicalismo movimientista", Revista Actuel Marx Intervenciones 13 (2012a): 95113. Santiago de Chile: LOM ediciones.

. "Dispositivos de disciplinamiento en el Trabajo. Relaciones laborales y subjetividad(es) en Chile", Revista Si Somos Americanos. Revista de Estudios Transfonterizos XII /2 (2012b): 109-131.

"La democracia formal y el fantasma terrorista. Una mirada a la paranoia estatal y su goce superyoico en Chile", International Journal of Zizek Studies 7/ 2 (2013a):

. "Contribuciones al estudio de Identidades e Identificaciones precarias en Chile”, Revista Polis 12/36 (2013b): 407-429.

Klein, Naomi. La Doctrina del shock. Barcelona: Paidós, 2007.

López, Diego. "El movimiento sindical en el gobierno de Michelle Bachelet: Nuevas acciones y Liderazgos". Análisis y Propuestas: Relaciones Industriales. Friedrich Ebert Stiftung [En línea]. Disponible en: http://library.fes.de/pdf-files/bueros/ chile/08579.pdf, 2009. [Consultado el: 12 de noviembre de 2012].

Moulián, Tomás. Chile Actual: Anatomía de un mito. Santiago de Chile: LOM ediciones, 2001. 
Paredes, José Luis. "Ciudadanía, Participación y Democracia Deuda y Déficit en los 20 años de "Democracia" en Chile", Revista Polis 10/28: (2011): 473-499.

Ricoeur, Paul. "El olvido en el horizonte de la prescripción”, 2002. En Academia Universal de las Culturas: ¿Por qué recordar? Argentina: Editorial Granica, (2007): 73-76.

Rojas, Hugo. "Las quejas ante el Comité de Libertad Sindical de la OIT durante el régimen militar". En Elizabeth Lira y Hugo Rojas (Eds.), Libertad Sindical y Derechos Humanos. Análisis de los informes del Comité de Libertad Sindical de la OIT (19731990). Santiago de Chile: Editorial LOM, 2009.

Salazar, Gabriel. La historia desde Abajo y desde Adentro. Santiago de Chile: LOM ediciones, 2003.

Salazar, Gabriel y Pinto, Julio. Historia Contemporánea de Chile, Volumen II: Actores, identidad y movimiento. Santiago de Chile: LOM Ediciones, 1999.

Salinero, Jorge. La destrucción del sindicato: Intolerancia a un derecho fundamental. Cuaderno de Investigación No 20. Santiago de Chile: Departamento de estudios de la Dirección del Trabajo, 2004.

La afiliación sindical y Negociación colectiva en Chile: Problemas y Desafíos. Cuaderno de Investigación $\mathrm{N}^{\circ} 29$. Santiago de Chile: Departamento de estudios de la Dirección del Trabajo, 2006.

Santucci, Antonio. Gramsi. Santiago de Chile: LOM ediciones, 2005.

Touraine, Alain. “Acción sindical y desigualdad social”, Proposiciones 17 (1989): 79-83.

Ulloa, Víctor. El movimiento sindical chileno. Del siglo XX hasta nuestros días. Santiago de Chile: Oficina Internacional del Trabajo, 2003.

Valenzuela, J. Samuel. "El movimiento obrero bajo el régimen militar”. En Francisco Zapata, "Clases sociales y acción obrera en Chile”. Jornada 110 - México: El Colegio de México, 1986.

Zapata, Francisco. "Transición democrática y el sindicalismo en Chile", Foro Internacional $130 / 2$ (1992): 703-721.

“¿Crisis del sindicalismo en América Latina?”, International Institute of Social History, 2003. Disponible en: http://kelogg.nd.edu/publications/workingpapers/WPS/302.pdf

. "De la democracia representativa a la democracia "protegida". Movimiento Obrero y sistema político en Chile", Revista Enfoques: Ciencia Política y Administración Pública 3 (2004): 125-155. 